\title{
CFD Simulation of Helical Shell and Tube Heat Exchanger Using Optimization Techniques
}

DOI:10.36909/jer.11985

\author{
Vivek Singh Parihar ${ }^{*}$, Shrikant Pandey ${ }^{*}$, Rakesh Kumar Malviya ${ }^{* *}$, Palash Goyal ${ }^{*}$ \\ *Mechanical Engineering Department, Shri Vaishnav Vidyapeeth Vishwavidyalaya, Indore, \\ 453111, Madhya Pradesh, India \\ ${ }^{* *}$ Corresponding Author - rakeshmalviya.2007@gmail.com
}

\begin{abstract}
The objective of this study is to simulate the performance of helical tube shell and tube heat exchanger with several optimization techniques using computational fluid dynamics CFD. To check the performance of a designed model of heat exchanger various techniques are available. In this study, the various possible model of the heat exchanger to enhance the performance of the device have been designed. Firstly, the straight tube is replaced by helical tube in the heat exchanger and used 10,12, 14 number of helical baffles with $50 \%$ baffle cut. Total ten models have been developed. These models are model-I 4-turns without baffle, model-II 4-turns with 10 number baffles, model-III 5-turns without baffle, model-IV 5-turns with 12 number baffles, model-V 6-turns without baffle, model-VI 6-turns with 10 number baffles $0.083 \mathrm{~m}$ baffle space, model-VII 6-turns with 12 number $0.083 \mathrm{~m}$ baffle space, modelVIII 6-turns with 14 number baffles $0.064 \mathrm{~m}$ baffle space, model-IX 7-turns without baffle, model-X 7-turns with 14 number baffles, different number of baffles and baffle space with $50 \%$ baffle cut and used CUO nanofluid model-XI 6-turns with 14 number baffle CUO fluid $0.083 \mathrm{~m}$ baffle space CFD analysis simulation done on ANSYS FLUENT 18. The simulated result shows that the model XI is approximately $40 \%$ more optimized as compared to model-I and approximately $24 \%$ than model-VIII. It also found that the high heat transfer obtains with increased number of baffles.
\end{abstract}

Keywords- STHXs, CUO, CFD, SOLIDWORKS, ANSYS FLUENT 18.

\section{INTRODUCTION}

Shell and tube heat exchanger STHXs are one of the most common types of exchangers which is used in the many engineering applications. These heat exchangers consist of a vessel with different sizes tubes inside. Several different methods have been studied to modify the shell and tube heat exchanger to make them more suitable for several applications. (Kishan et al., 2020) have designed tube and box heat exchanger with various pattern of tubes to investigate the flow and temperature field in heat exchanger using ANSYS programming tool. Three types of heat exchangers they have planned in this examination with various structures of cylinders contains of $175 \mathrm{~mm}$ breadth and $1000 \mathrm{~mm}$ length shell measurement $175 \mathrm{~mm}$. Advancement is done which tries to distinguish the best parameter combination of heat exchangers to enhance the rate of heat exchange in heat exchanger. The prefix parameter (tube width) is utilized as an info variable and the yield parameter is the most extreme temperature distinction of container and tube heat exchanger.

(Perone et al.,2021) showed that the use of a heat exchanger for the conditioning of the olive paste could enhance the olive oil extraction process. Particularly, paste pre-heating could 
reduce the malaxation time and, most of all, improve the temperature control during this process. A three-dimensional computational fluid dynamics (CFD) analysis of a tubular heat exchanger was carried out to better understand the influence of the inlet conditions of the olive paste on thermal and hydrodynamic behaviour within it and predict the heat transfer and pressure drop in paste side of the exchanger. Multiple analyses by varying the mass flow rate and inlet temperature of the paste were carried out, and temperature and pressure drop were estimated. The numerical model has proved very useful in identifying the main factors affecting the optimization of the heat exchanger to improve the extraction process of the olive paste.

Aydin et al., 2020 studied the flow analysis of the optimized heat exchanger has been carried out to reveal possible flow field and temperature distribution inside the equipment using computational fluid dynamics. The experimental results were compared with computational fluid dynamics analyses results. It has been concluded that the baffles play an important role in the development of the shell side flow field. It has been found that the heat exchanger with the new baffle design gives rise to considerably lower pressure drops in the shell side, which in turn reducing operating cost.

Yang et al. 2016 studied about the combined analysis of serial two shell-pass shell-and-tube heat exchanger CSTSP-STHXs with continuous helical baffle and improved the heat transfer performance. Wang et al. 2008 conclude that blocking the gap between the baffle plates and shell by use of sealer which effectively decreases the short-circuit flow in the shell-side and overall heat transfer coefficient heat transfer increased by 15.6-19.7\%. Taher et al. 2012 is tested the effect of baffle space in different cases on heat transfer of exchanger. Avval and Damangir 1994 investigated optimal baffle spacing for all types of shell and tube exchangers in which found a high heat transfer coefficient and optimal pressure drop. Wang et al. 2011 investigated experimentally of shell-and-tube heat exchanger with a new type of baffles for improving the heat transfer and pressure drop performance. Genic et al. 2012 done experiments on the shell-side thermal performances of heat exchangers with helical tube coils and define that shell-side heat transfer coefficients should be based on shell-side hydraulic diameter. Abd et al. 2018 investigated the effect of shell diameter and tube length on heat transfer coefficient and pressure drop for shell side with both triangular and square pitches and also studied the effect of baffle spacing and cutting space on heat transfer coefficient and pressure drop. Dong et al. 2015 examined the Flow and heat transfer performances of helical baffle heat exchangers with different baffle configurations and select one of them which has a high heat transfer rate. So, all the study, investigation and experiments represent how to get the highest heat transfer rate and optimal pressure drop with certain parameters and operating conditions which is most beneficial in all industrial processes.

To enhancing the performance of heat exchanger by changing the geometry of tube and shell, use optimal baffles and baffle angles still needs to be investigated. The main objective of this paper is to shows the effect of the increasing number of turns in the helical tube and use of optimal baffles on device performance with nanofluids.3D model of the heat exchanger and helical tube is designed in SOLIDWORKS 2017, and then CFD analysis on ANSYS fluent 18 has been done.

The paper is organized in seven sections including introduction. Section two presents the objective of the study. Section three deals with the methodology adopted for the study. Section four presents modelling of the study. In section fifth analysis of models is done. 
Section six deals with the results and discussion followed by conclusion of the study in section seven.

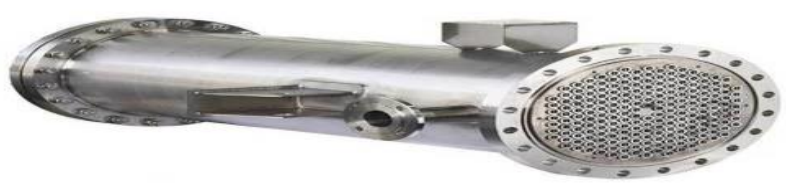

Figure 1. Shell and Tube Heat Exchanger

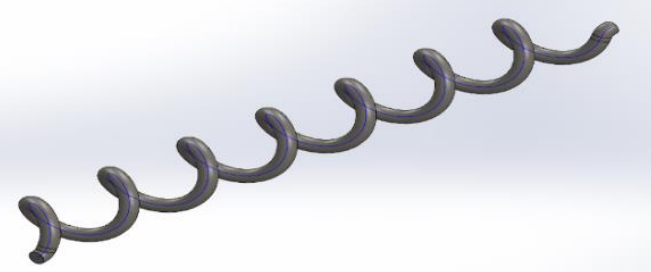

Figure 2. Helical tube of heat exchanger 


\section{METHODOLOGY}

In this study CAD software, namely SOLIDWORKS and analysis software namely ANSYS 18.0 are used for achieving the objective of the research. So, in this study explanatory type research is used and describes the methodology in stepped flow diagram-

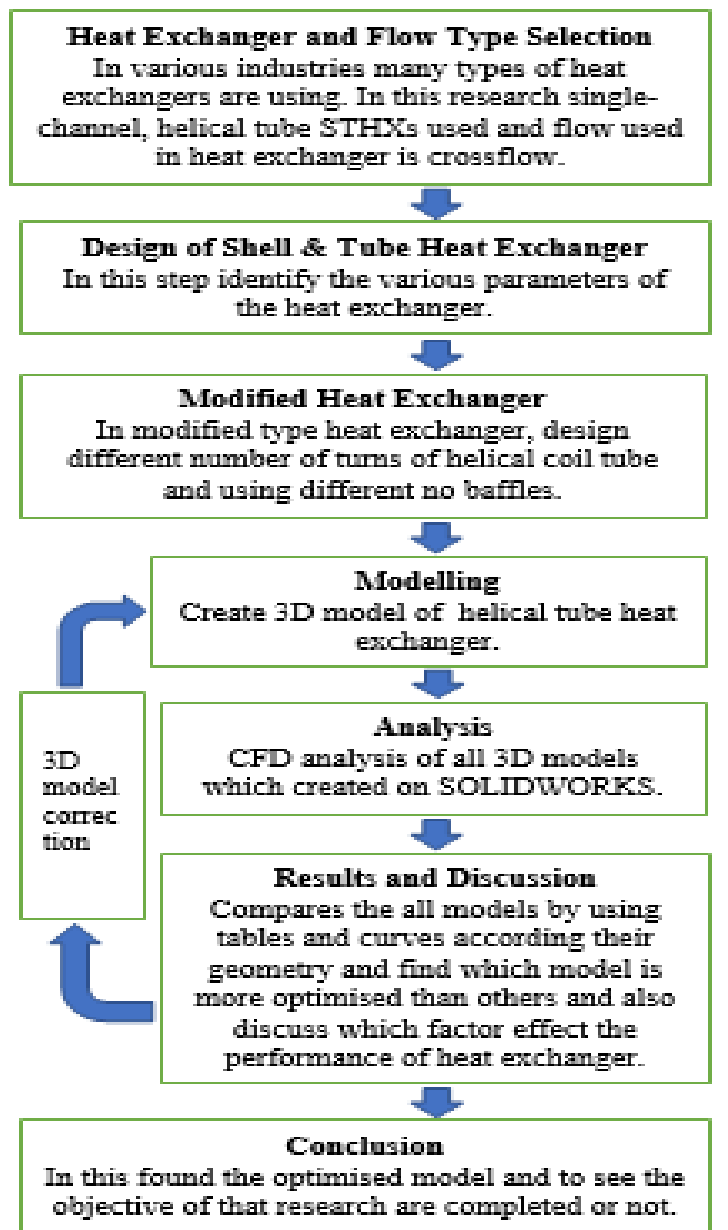

Figure 3. Regearch methodology of Heat Exchanger 


\section{MODELLING}

The designed parameters of modified type shell and tube heat exchanger without discontinuous segmental baffle and with discontinuous segmental baffle are defined belowModified Design Parameters-

Table 1- Design parameters of modified heat exchanger

\begin{tabular}{|c|c|c|}
\hline S.No & Parameter & Dimension \\
\hline 1 & Shell diameter & $0.091 \mathrm{~m}$ \\
\hline 2 & Shell length & $0.52 \mathrm{~m}$ \\
\hline 3 & Shell thickness & $0.003 \mathrm{~m}$ \\
\hline 4 & Tube diameter & $0.013 \mathrm{~m}$ \\
\hline 5 & Tube length & $0.52 \mathrm{~m}$ \\
\hline 6 & Tube thickness & $0.001 \mathrm{~m}$ \\
\hline 7 & Tube pitch type & Rectangular \\
\hline 8 & Number of tubes required & 4 \\
\hline 9 & umber of baffles required 4-Tur & 10 \\
\hline 10 & 10 Baffle spacing 4-Turns & $0.094 \mathrm{~m}$ \\
\hline 11 & umber of baffles required 5-Tur & 12 \\
\hline 12 & 12 Baffle spacing 5-Turns & $0.076 \mathrm{~m}$ \\
\hline 13 & umber of baffles required 6-Tur & 14 \\
\hline 14 & 14 Baffle spacing 6-Turns & $0.063 \mathrm{~m}$ \\
\hline 15 & umber of baffles required 6-Tur & 12 \\
\hline 16 & 12 Baffle spacing 6-Turns & $0.083 \mathrm{~m}$ \\
\hline 17 & umber of baffles required 6-Tur & 10 \\
\hline 18 & 10 Baffle spacing 6-Turns & $0.083 \mathrm{~m}$ \\
\hline 19 & umber of baffles required 7-Tur & 14 \\
\hline 20 & Baffle spacing 7-Turns & $0.063 \mathrm{~m}$ \\
\hline 21 & Shell inlet diameter & $0.02 \mathrm{~m}$ \\
\hline 22 & Shell outlet diameter & $0.02 \mathrm{~m}$ \\
\hline
\end{tabular}




\section{Model-I}

Modified type 4-Turns helical tube shell and tube heat exchanger without baffle-

Isometric view-

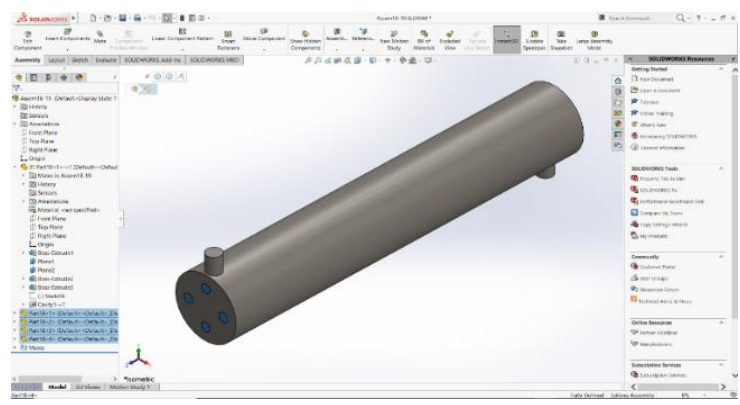

Figure 1 Isometric view of 4-Turns of helical tube STHXs

Internal view-

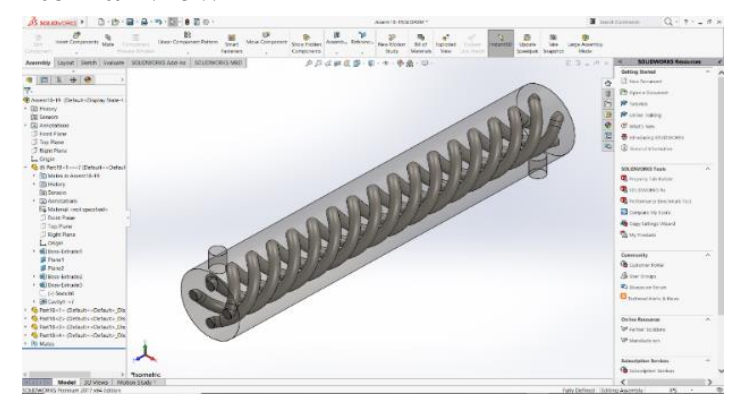

Figure 2 Internal view of 4-Turns of helical tube STHXs

\section{Model-II}

Modified type 4-Turns helical tube shell and tube heat exchanger with baffle-

Internal view-

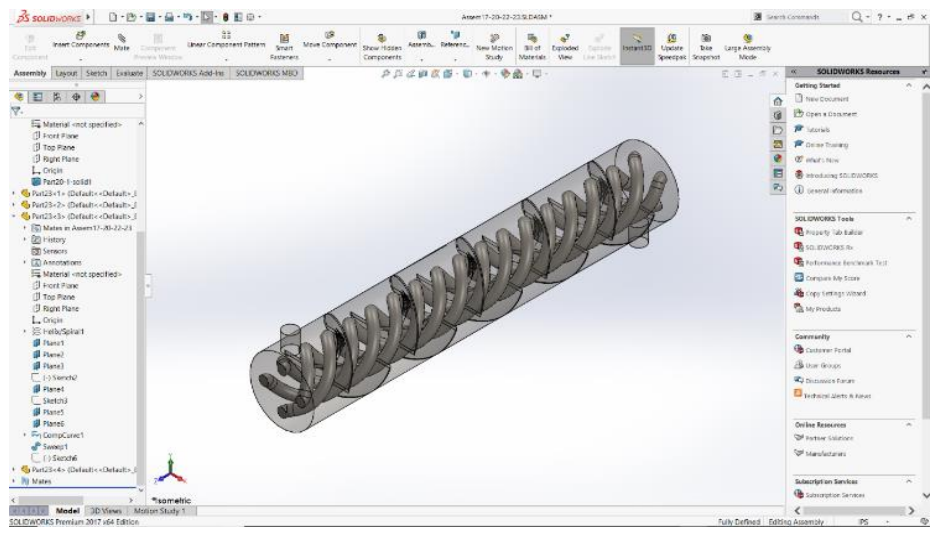

Figure 3 Internal view of 4-Turns with 10 number baffles of helical tube STHXs 
Isometric view-

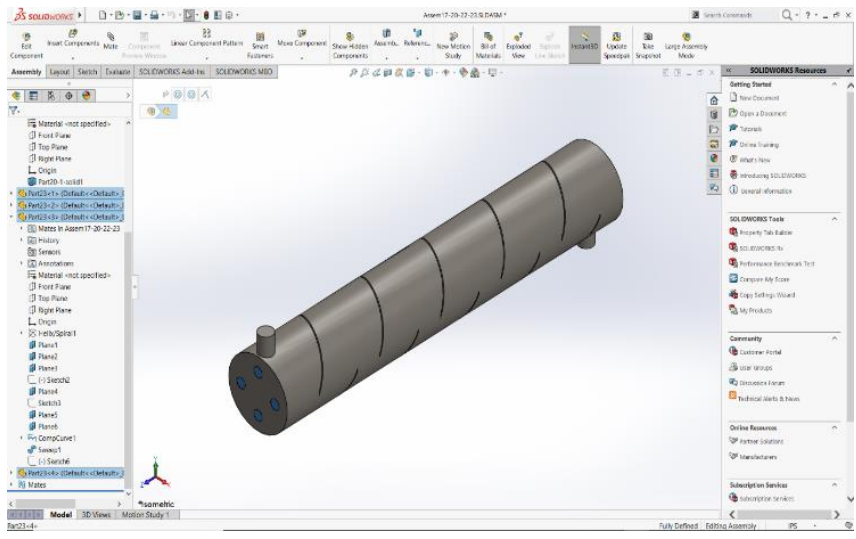

Figure 4 Isometric view of 4-Turns with 10 number baffles of helical tube STHXs

\section{Model-III}

Modified type 5-Turns helical tube shell and tube heat exchanger without baffle-

Isometric view-

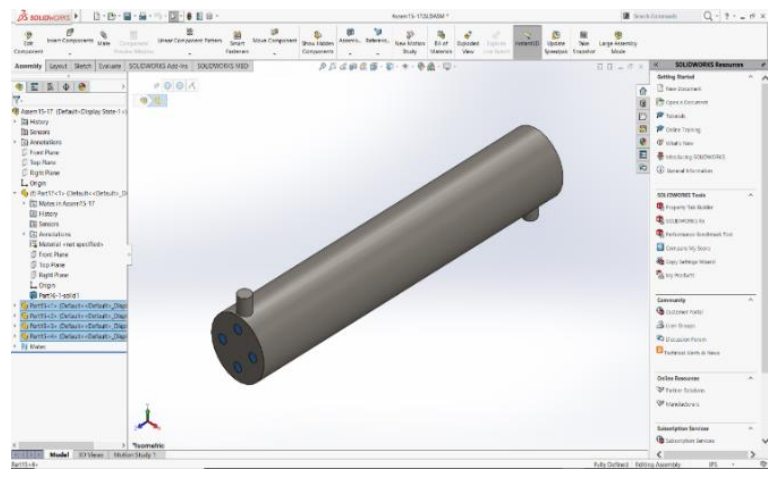

Figure 5 Isometric view of 5-Turns of helical tube STHXs

Internal view-

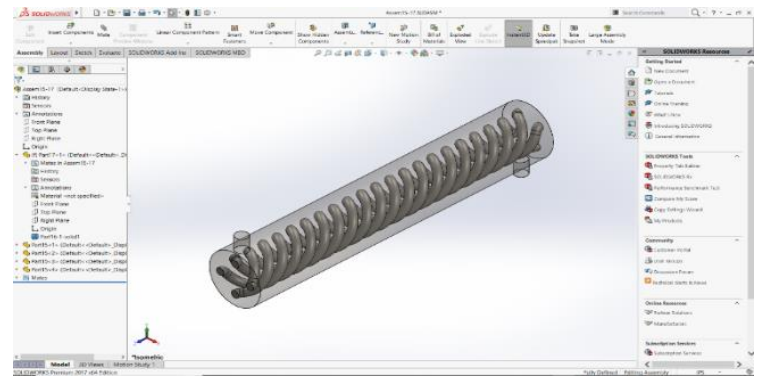

Figure 6 Internal view of 5-Turns of helical tube STHXs 


\section{Model-IV}

Modified type 5-Turns helical tube shell and tube heat exchanger with 12 baffle-

Isometric view-

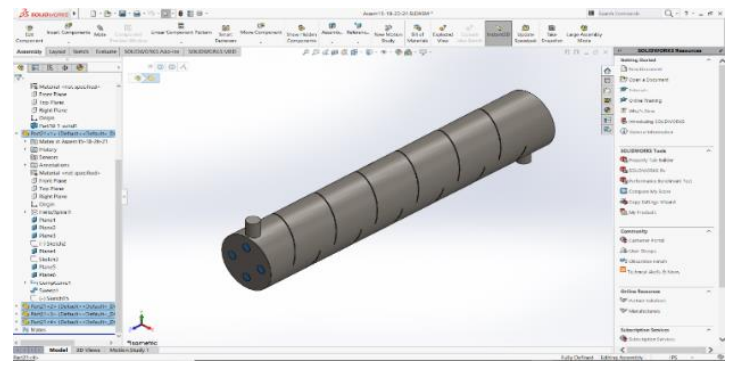

Figure 7 Isometric view of 5-Turns with 12

number baffles of helical tube STHXs

Internal view-

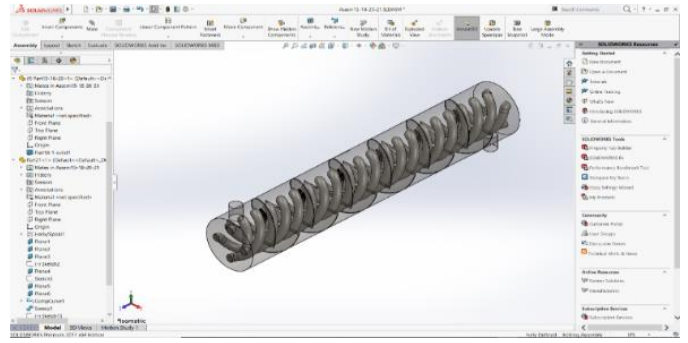

Figure 8 Internal view of 5-Turns with 12 number baffles of helical tube STHXs

\section{Model-V}

Modified type 6-Turns helical tube shell and tube heat exchanger without baffle

Isometric view-

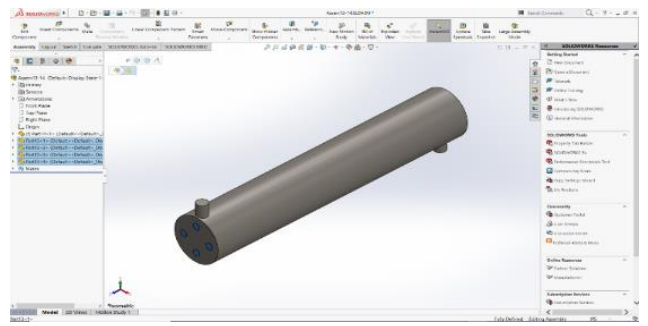

Figure 9 Isometric view of 6-Turns of helical tube STHXs

Internal view-

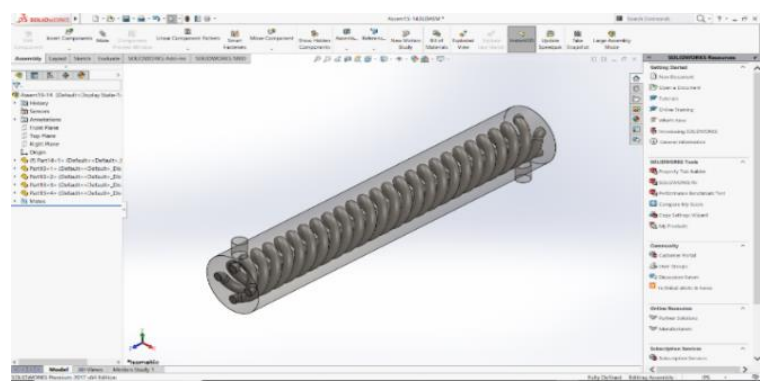

Figure 10 Internal view of 6-Turns of helical tube STHXs 


\section{Model-VI}

Modified type 6-Turns helical tube shell and tube heat exchanger with 10 baffle-

Isometric view-

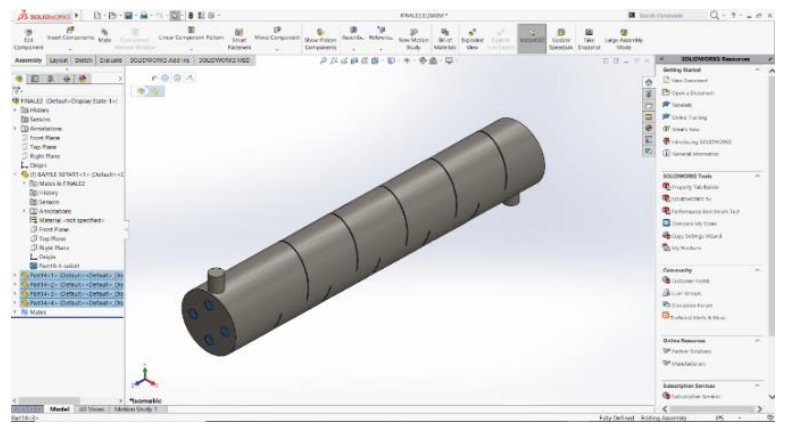

Figure 11 Isometric view of 6-Turns with 10 number baffles of helical tube STHXs

Internal view-

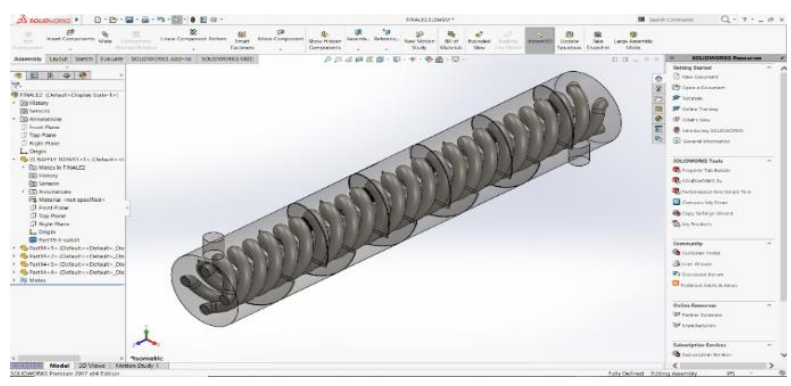

Figure 12 Internal view of 6-Turns with 10 number baffles of helical tube STHXs

\section{Model-VII}

Modified type 6-Turns helical tube shell and tube heat exchanger with 12 baffle-

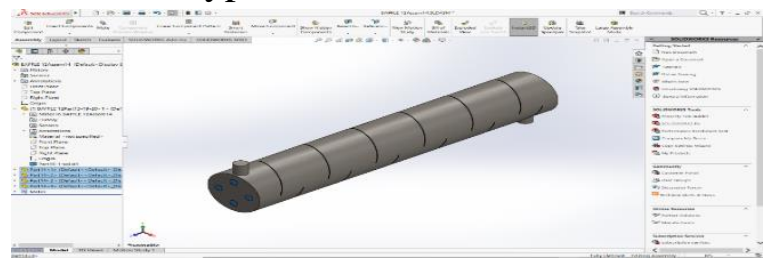

Figure 13 Isometric view of 6-Turns with 12 number baffles of helical tube STHXs

Internal view-

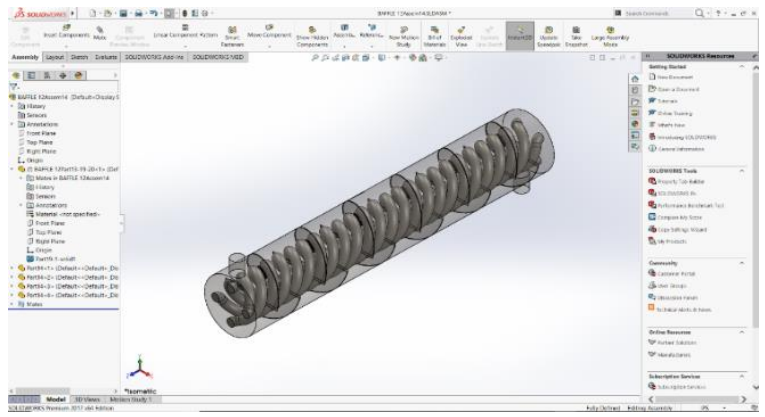

Figure 14 Internal view of 6-Turns with 12 number baffles of helical tube STHXs 


\section{Model-VIII}

Modified type 6-Turns helical tube shell and tube heat exchanger with 14 baffle-

Isometric view-

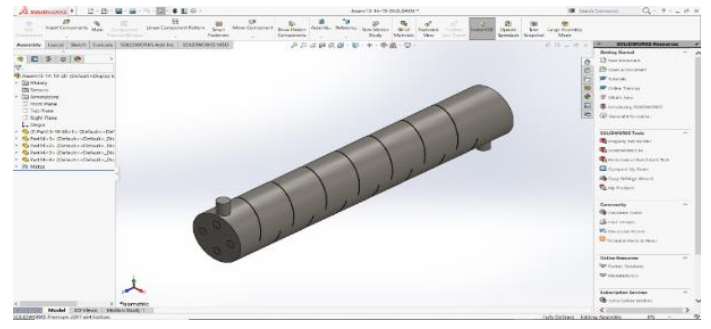

Figure 15 Isometric view of 6-Turns with 14 number baffles of helical tube STHXs

Internal view-

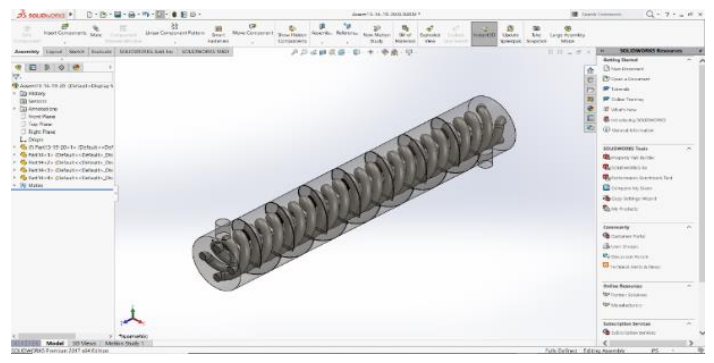

Figure 16 Internal view of 6-Turns with 14 number baffles of helical tube STHXs

\section{Model-IX}

Modified type 7-Turns helical tube shell and tube heat exchanger without baffle-

Isometric view-

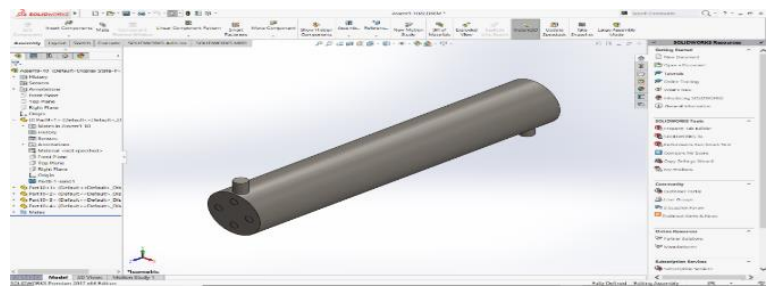

Figure 17 Isometric view of 7-Turns of helical tube STHXs

Internal view-

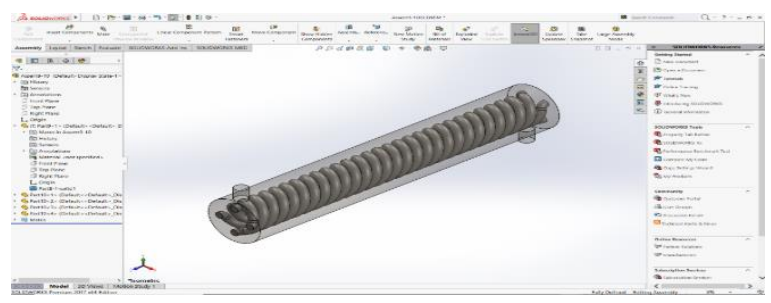

Figure 18 Internal view of 7-Turns of helical tube STHXs 


\section{Model-X}

Modified type 7-Turns helical tube shell and tube heat exchanger with 14 baffle-

Isometric view-

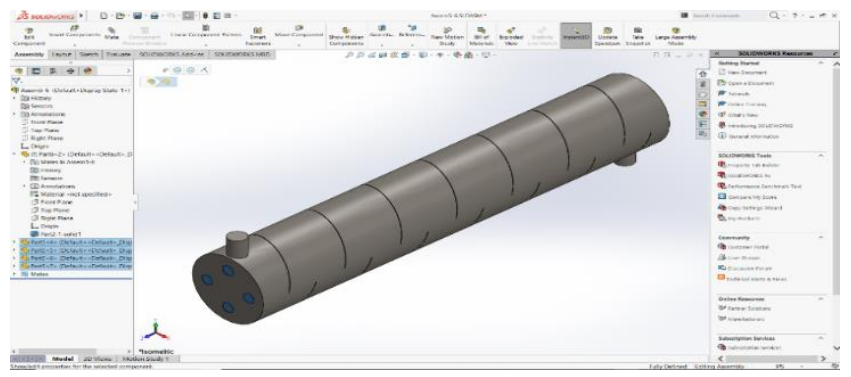

Figure 19 Isometric view of 7-Turns with 14 number baffles of helical tube STHXs Internal view-

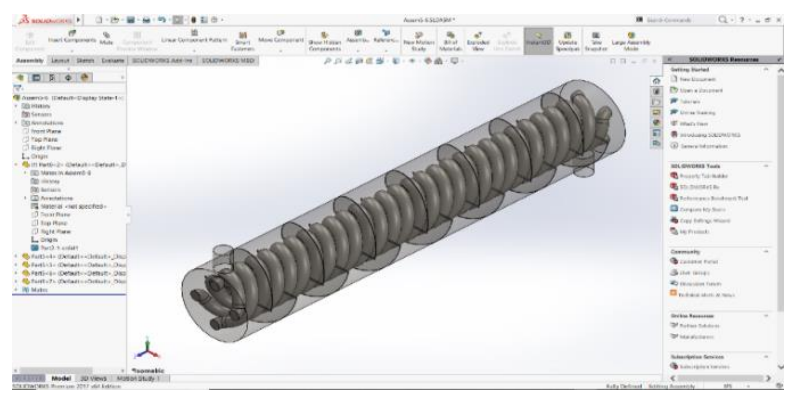

Figure 20 Isometric view of 7-Turns with 14 number baffles of helical tube STHXs 


\section{ANALYSIS}

The analysis data input for modified type shell and tube heat exchanger without discontinuous segmental baffle and with discontinuous segmental baffle are defined below-

\section{Analysis Parameters-}

\begin{tabular}{|c|c|}
\hline Fluid type & $\begin{array}{l}\text { water fluid and CUO- } \\
\text { water nano fluid }\end{array}$ \\
\hline $\begin{array}{l}\text { Nano fluid } \\
\text { property }\end{array}$ & $\begin{array}{l}\text { Specific heat } 540 \mathrm{~J} / \mathrm{kg} \\
\mathrm{K}, \text { Density } 6510 \\
\mathrm{Kg} / \mathrm{m} 3 \text {, Thermal } \\
\text { conductivity } 18 \\
\mathrm{~W} / \mathrm{mK} \text {. }\end{array}$ \\
\hline Flow type & Counter flow \\
\hline $\begin{array}{l}\text { Inlet } \\
\text { temperature of } \\
\text { hot fluid }\end{array}$ & $90^{\circ} \mathrm{C}$ \\
\hline $\begin{array}{l}\text { Inlet velocity of } \\
\text { hot fluid }\end{array}$ & $0.4 \mathrm{~m} / \mathrm{s}$ \\
\hline $\begin{array}{l}\text { Inlet } \\
\text { temperature of } \\
\text { cold fluid }\end{array}$ & $26^{\circ} \mathrm{C}$ \\
\hline $\begin{array}{l}\text { Inlet velocity of } \\
\text { cold fluid }\end{array}$ & $0.5 \mathrm{~m} / \mathrm{s}$ \\
\hline Initialisation & Standard \\
\hline $\begin{array}{l}\text { Environmental } \\
\text { Condition }\end{array}$ & $27^{\circ} \mathrm{C}, 1 \mathrm{~atm}$ \\
\hline
\end{tabular}




\section{Model-I}

Modified 4-Turns Helical Tube shell and tube heat exchanger without baffles-

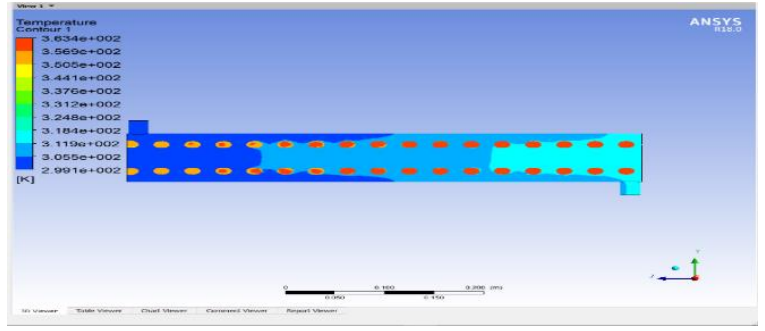

Figure 21 Temperature view of 4-Turns of helical tube STHXs

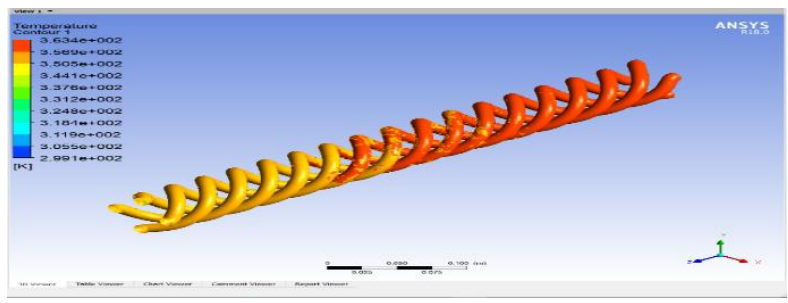

Figure 22 Tube view of 4-Turns of helical tube STHXs

\section{Shell side-}

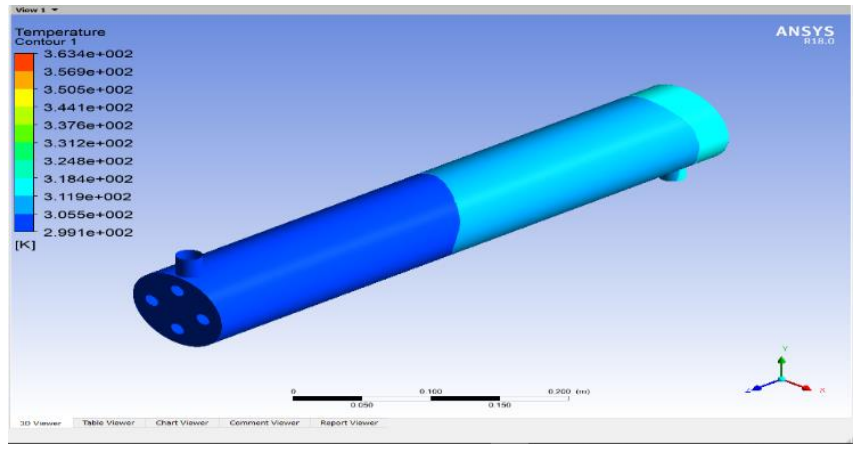

Figure 23 Shell view of 4-Turns of helical tube STHXs

Mesh model-

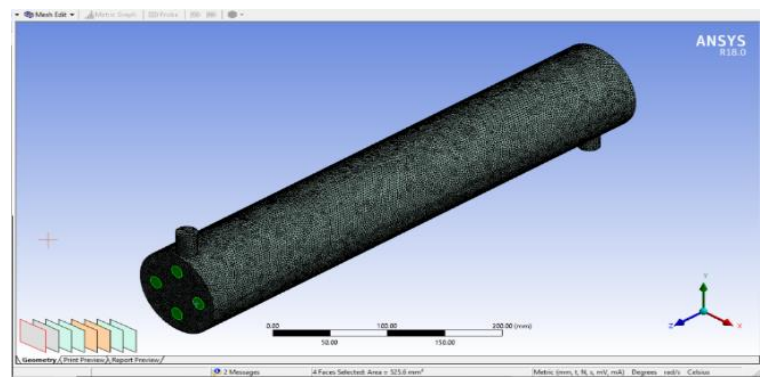




\section{Model-II}

Modified 4-Turns Helical Tube shell and tube heat exchanger with 10 baffles-

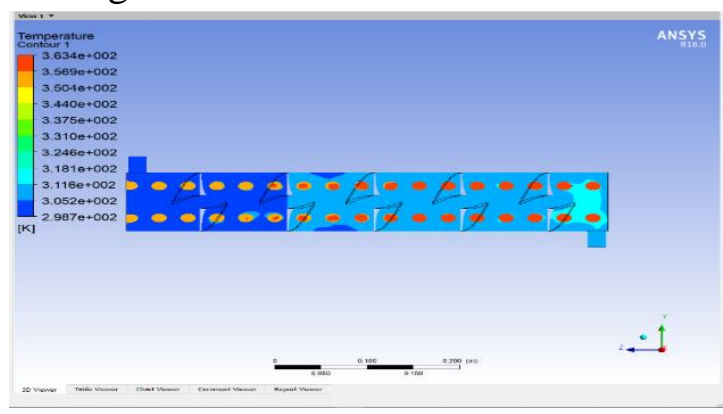

Figure 24 Temperature view of 4-Turns with 10 number baffles of helical tube STHXs

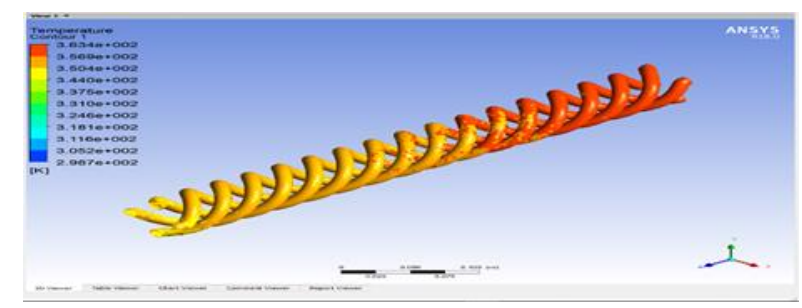

Figure 25 Tube view of 4-Turns with 10 number baffles of helical tube STHXs

Shell side-

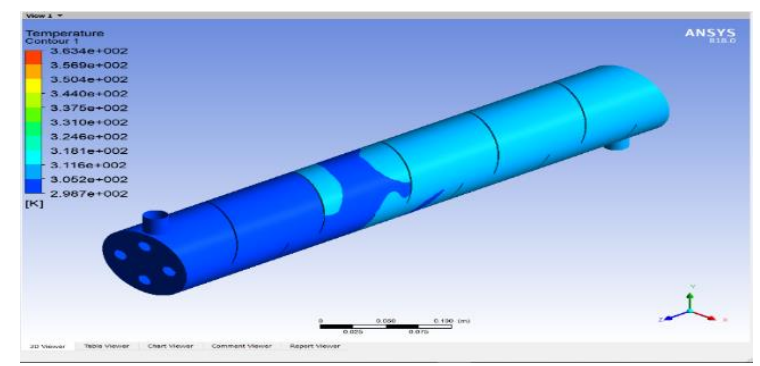

Figure 26 Shell view of 4-Turns with 10 number baffles of helical tube STHXs

Mesh model-

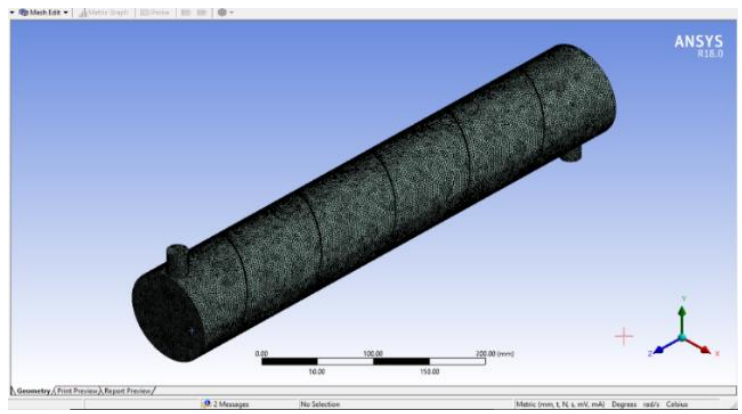

Figure 26 Mesh model of 4-Turns with 10 number baffles of helical tube STHXs 


\section{Model-III}

Modified 5-Turns Helical Tube shell and tube heat exchanger without baffles-

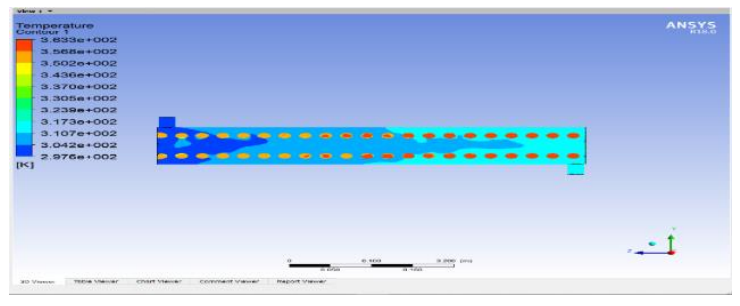

Figure 28 Temperature view of 5-Turns of helical tube STHXs

Tube side-

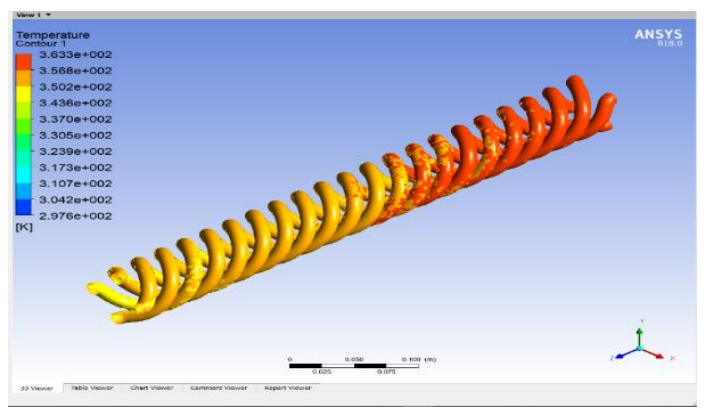

Figure 29 Tube view of 5-Turns of helical tube STHXs

Shell side-

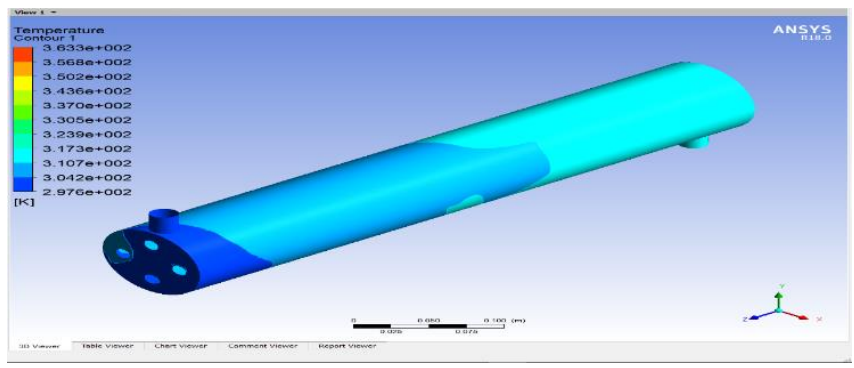

Figure 30 Shell view of 5-Turns of helical tube STHXs

Mesh model-

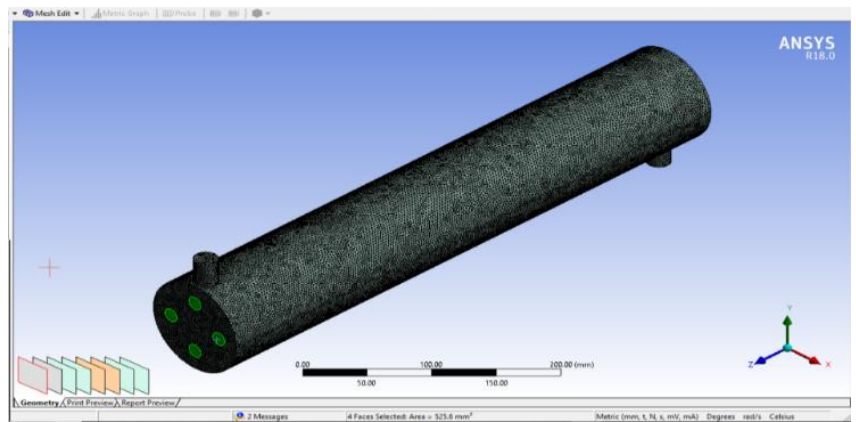

Figure 31 Mesh model of 5-Turns of helical tube STHXs 


\section{Model-IV}

Modified 5-Turns Helical Tube shell and tube heat exchanger with 12 baffles-

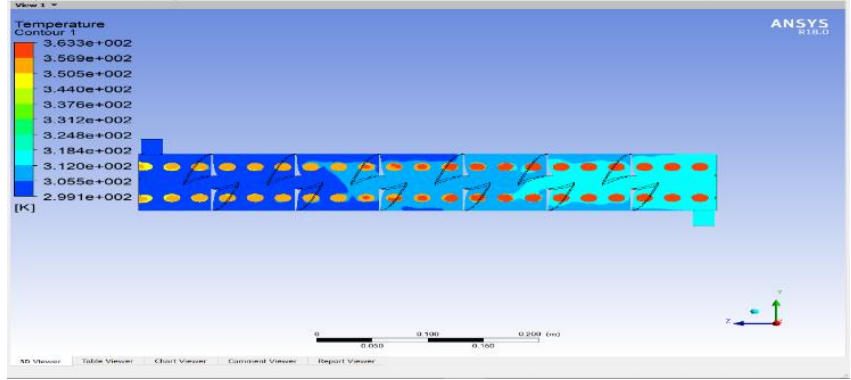

Figure 33 Temperature view of 5-Turns with 12 number baffles of helical tube STHXs

Tube side-

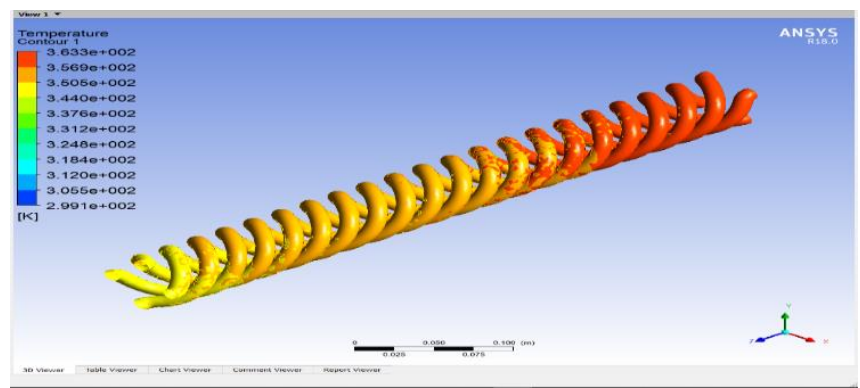

Figure 34 Tube view of 5-Turns with 12 number baffles of helical tube STHXs

Shell side-

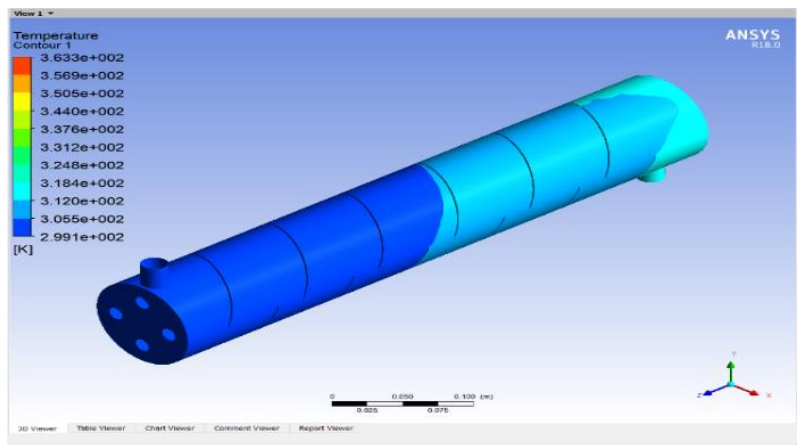

Figure 35 Shell view of 5-Turns with 12 number baffles of helical tube STHXs 
Mesh model-

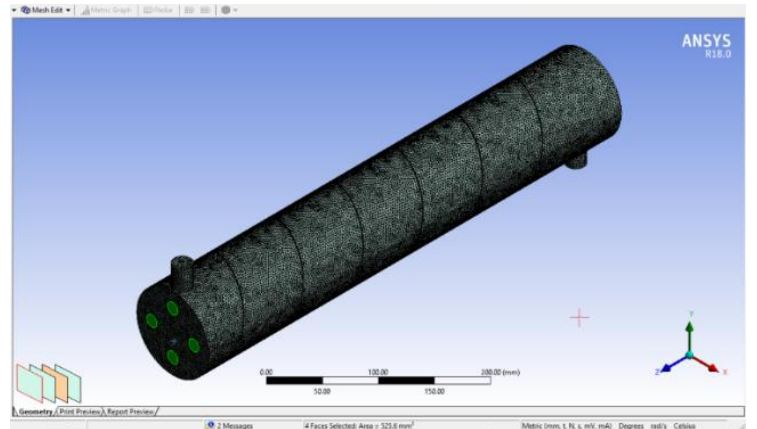

Figure 36 Mesh model of 5-Turns with 12 number baffles of helical tube STHXs

\section{Model-V}

Modified 6-Turns Helical Tube shell and tube heat exchanger without baffles-

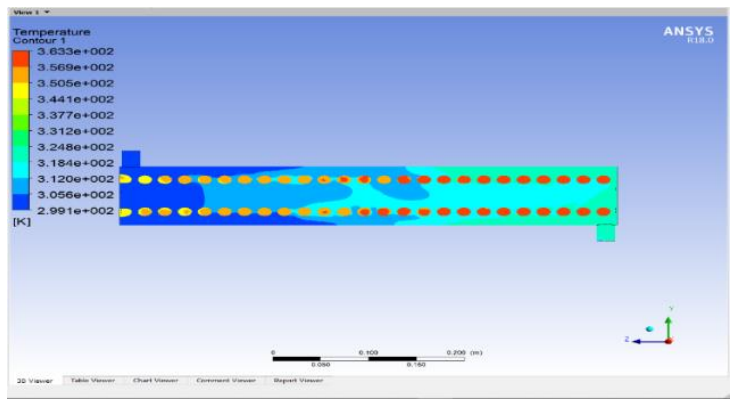

Figure 38 Temperature view of 6-Turns of helical tube STHXs

Tube side-

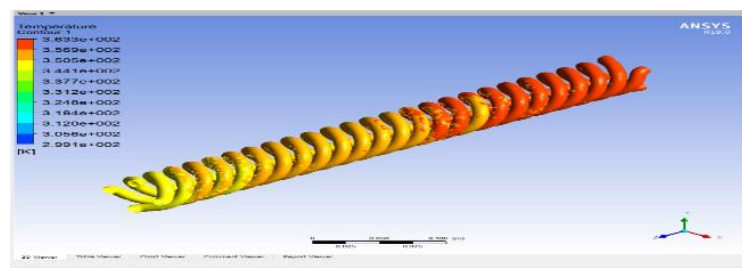

Figure 39 Tube view of 6-Turns of helical tube STHXs

Shell side-

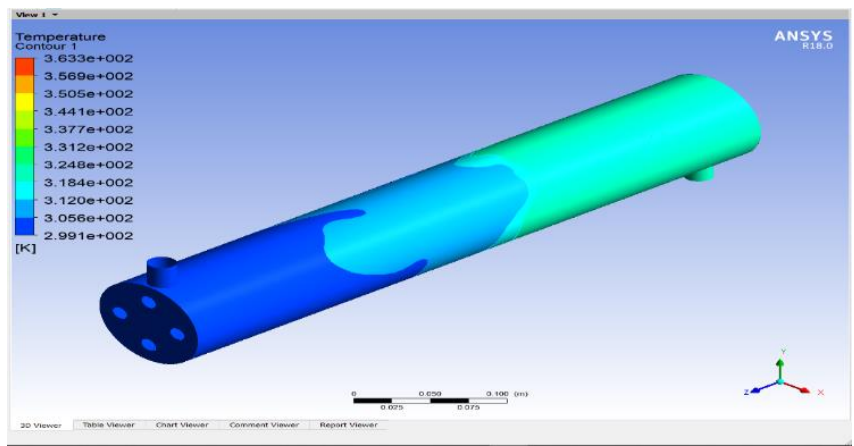

Figure 40 Shell view of 6-Turns of helical tube STHXs 
Mesh model-

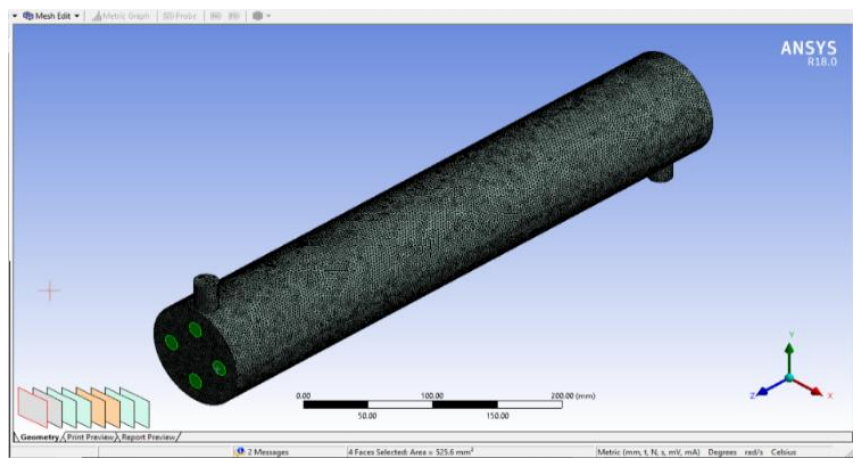

Figure 41 Mesh model of 6-Turns of helical tube STHXs

\section{Model-VI}

Modified 6-Turns Helical Tube shell and tube heat exchanger with 10 baffles-

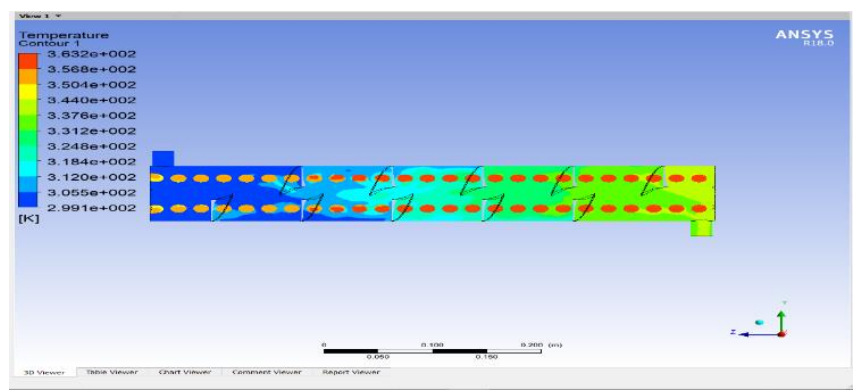

Figure 43 Temperature view of 6-Turns with 10 number baffles of helical tube STHXs

Tube side-

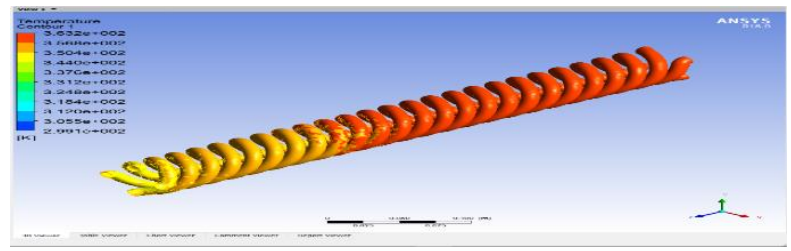

Figure 44 Tube view of 6-Turns with 10 number baffles of helical tube STHXs

Shell side-

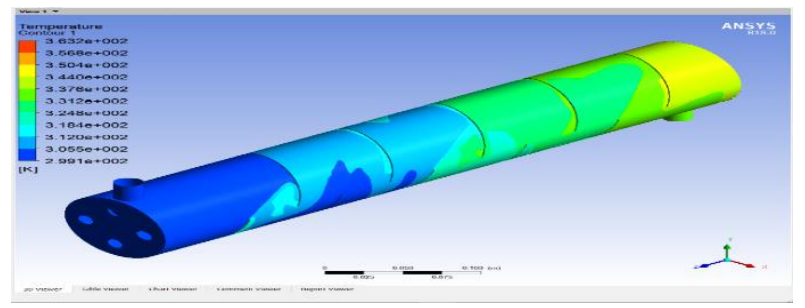

Figure 45 Shell view of 6-Turns with 10 number baffles of helical tube STHXs 
Mesh model-

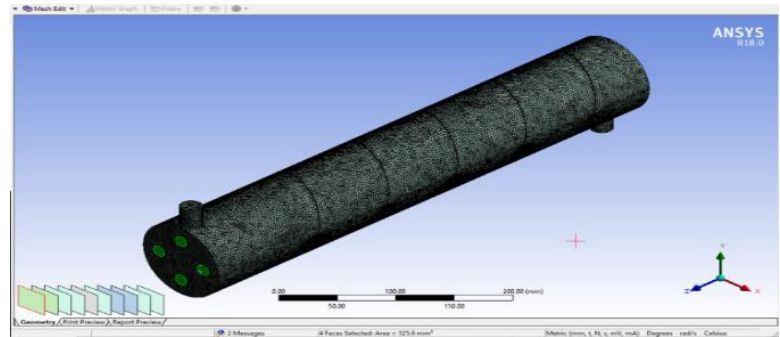

Figure 46 Mesh model of 6-Turns with 10 number baffles of helical tube STHXs

\section{Model-VII}

Modified 6-Turns Helical Tube shell and tube heat exchanger with 12 baffles-

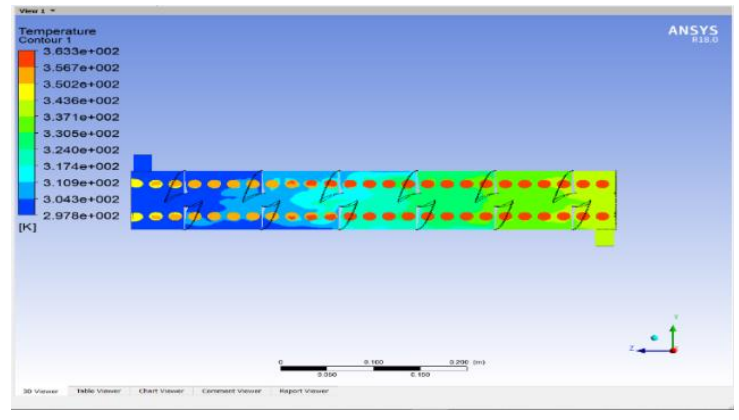

Figure 48 Temperature view of 6-Turns with 12 number baffles of helical tube STHXs

Tube side-

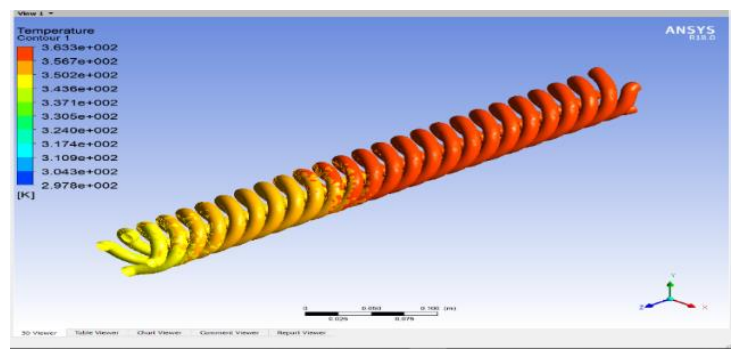

Figure 49 Tube view of 6-Turns with 12 number baffles of helical tube STHXs

Shell side-

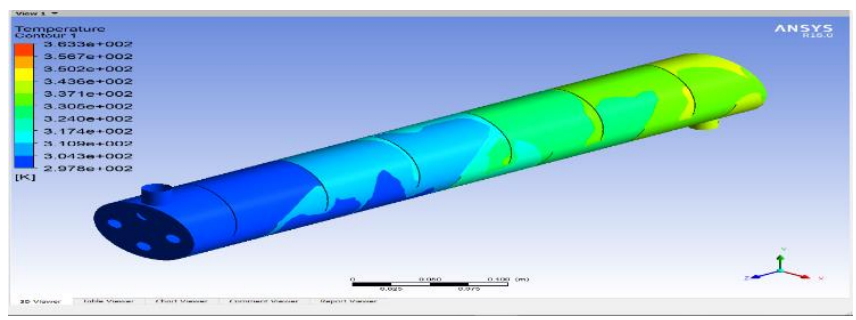

Figure 50 Shell view of 6-Turns with 12 number baffles of helical tube STHXs

Mesh model- 


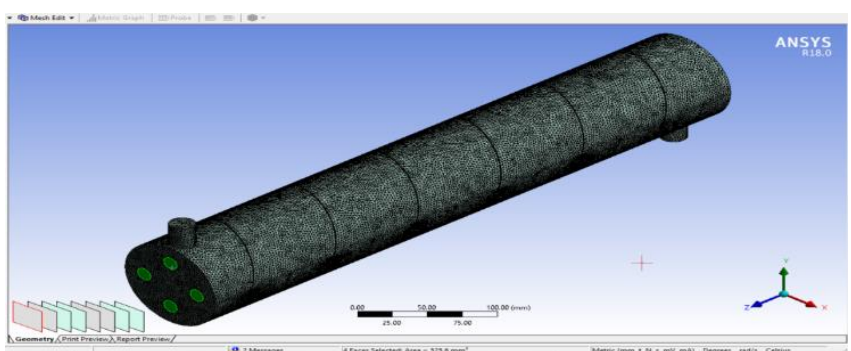

Figure 51 Mesh model of 6-Turns with 12 number baffles of helical tube STHXs

\section{Model-VIII}

Modified 6-Turns Helical Tube shell and tube heat exchanger with 14 baffles-

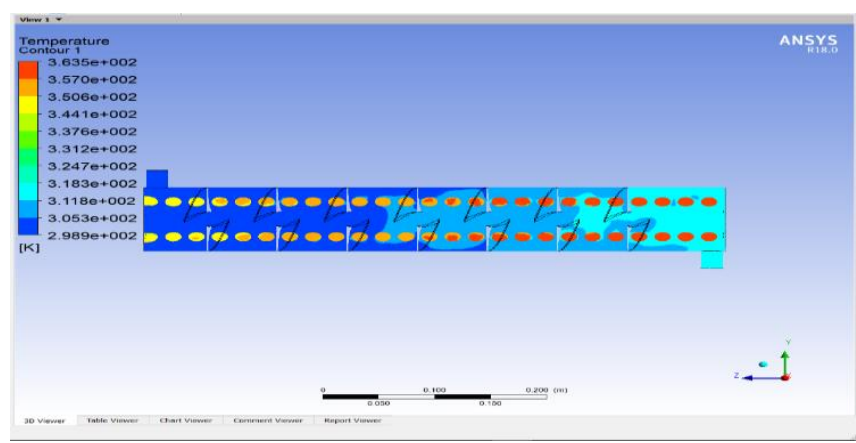

Figure 53 Temperature view of 6-Turns with 14 number baffles of helical tube STHXs

Tube side-

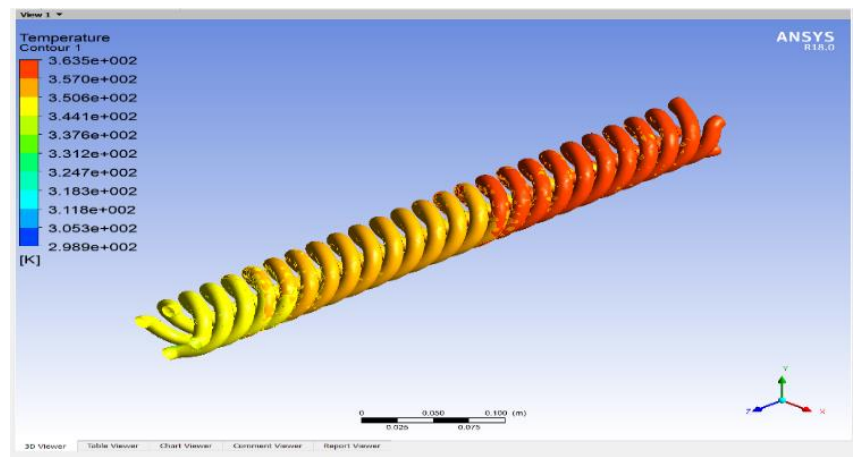

Figure 54 Tube view of 6-Turns with 12 number baffles of helical tube STHXs

Shell side-

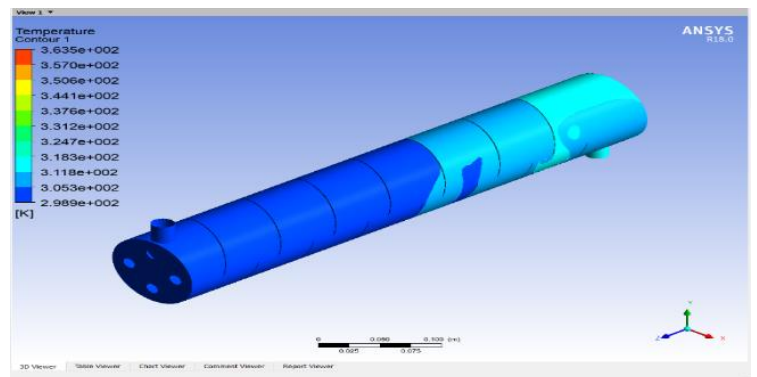

Figure 55 Shell view of 6-Turns with 14 number baffles of helical tube STHXs 
Mesh model-

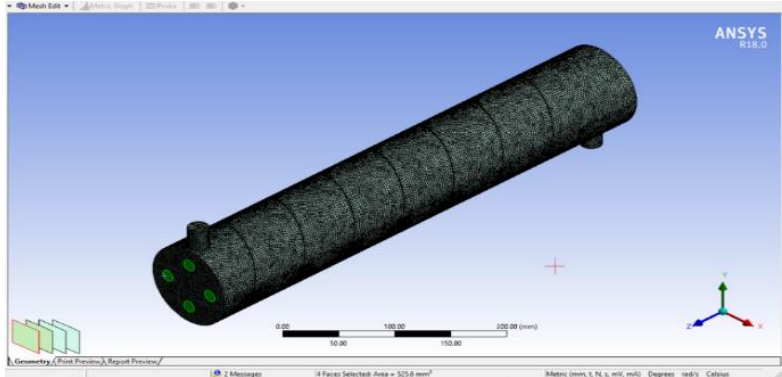

Figure 56 Mesh model of 6-Turns with 14 number baffles of helical tube STHXs

\section{Model-IX}

Modified 7-Turns Helical Tube shell and tube heat exchanger without baffles-

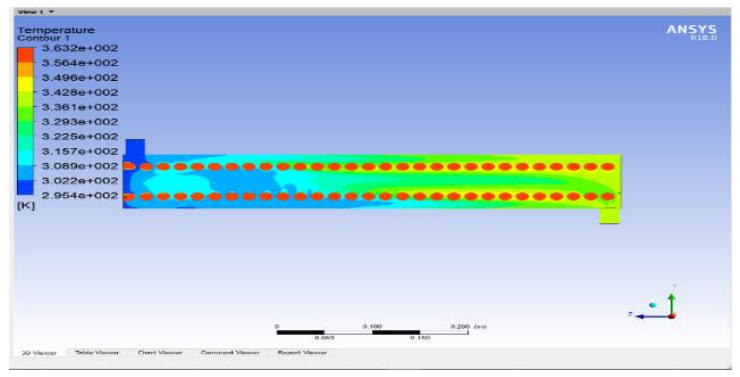

Figure 58 Temperature view of 7-Turns of helical tube STHXs

Tube side-

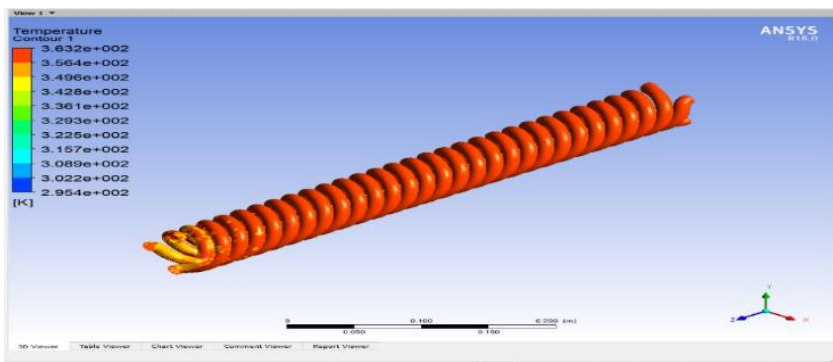

Figure 59 Tube view of 7-Turns of helical tube STHXs

Shell side-

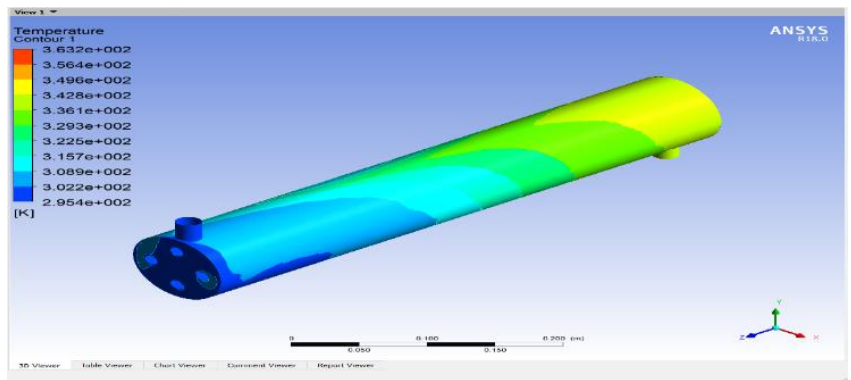

Figure 60 Shell view of 7-Turns of helical tube STHXs 
Mesh model-

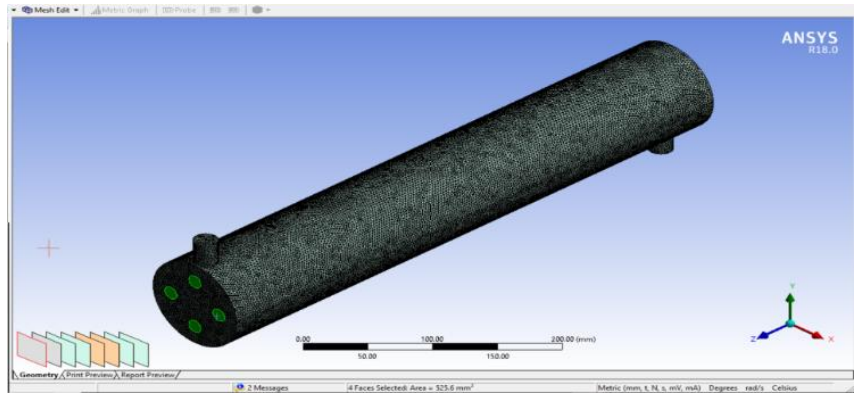

Figure 61 Mesh model of 7-Turns of helical tube STHXs

\section{Model-X}

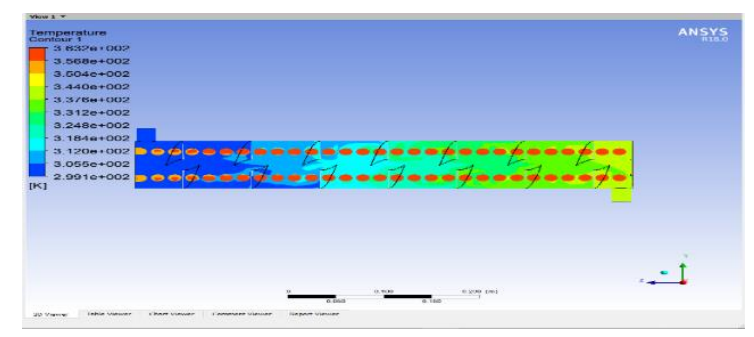

Figure $\mathbf{6 3}$ Temperature view of 7-Turns with 14 number baffles of helical tube STHXs

Tube side-

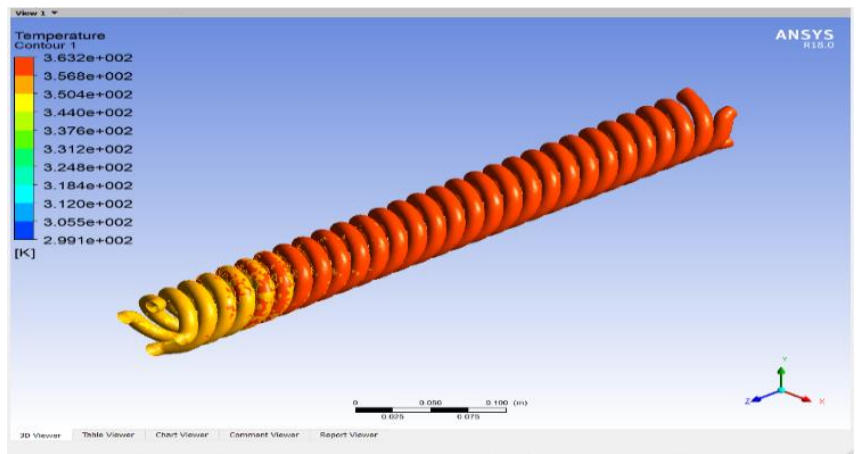

Figure 64 Tube view of 7-Turns with 14 number baffles of helical tube STHXs

Shell side-

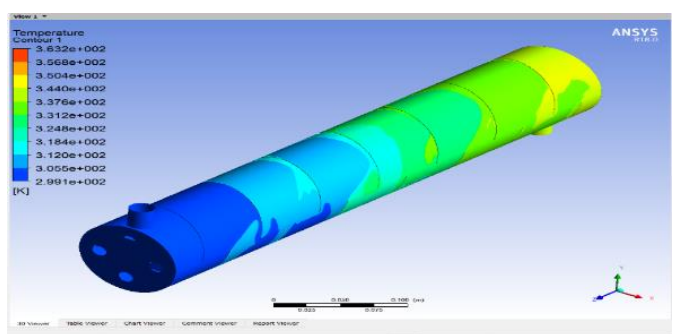

Figure 65 Shell view of 7-Turns with 14 number baffles of helical tube STHXs 
Mesh model-

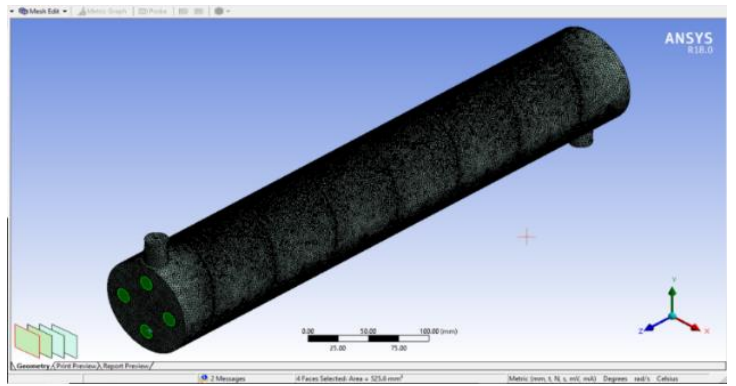

Figure 63 Mesh model of 7-Turns with 14 number baffles of helical tube STHXs

\section{Model-XI}

Modified 6-Turns Helical Tube CUO shell and tube heat exchanger with baffles-

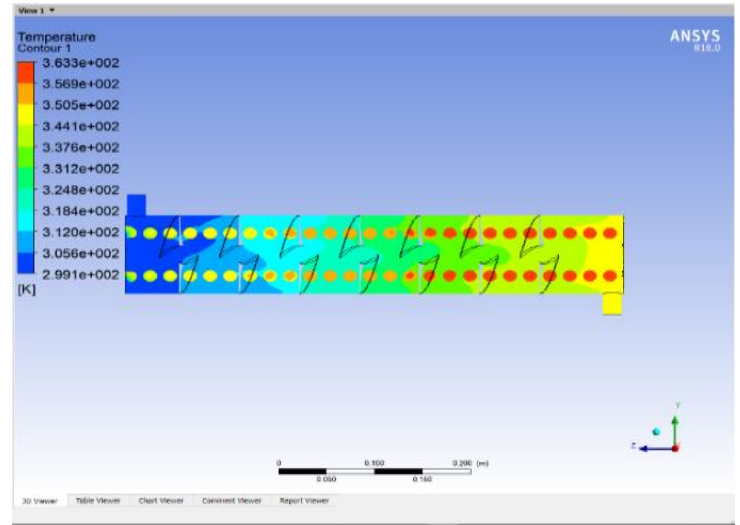

Figure 65 Temperature view of 6-Turns CUO model with 14 number baffles of helical tube STHXs

Tube side-

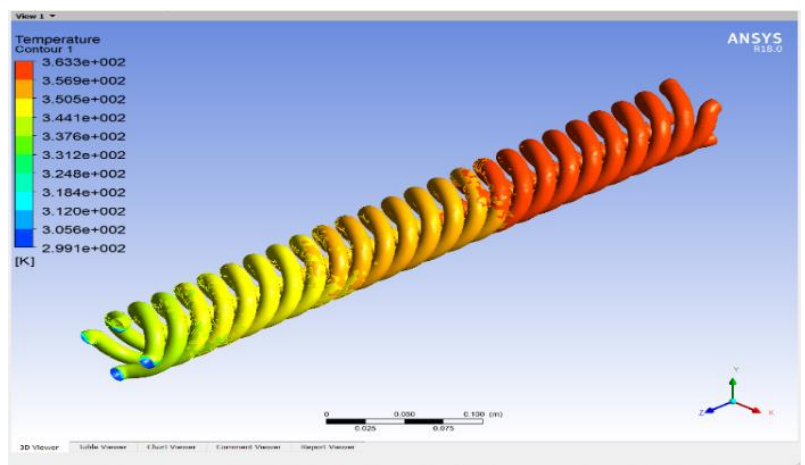

Figure 66 Tube view of 6-Turns CUO model with 14 number baffles of helical tube STHXs 


\section{Shell side-}

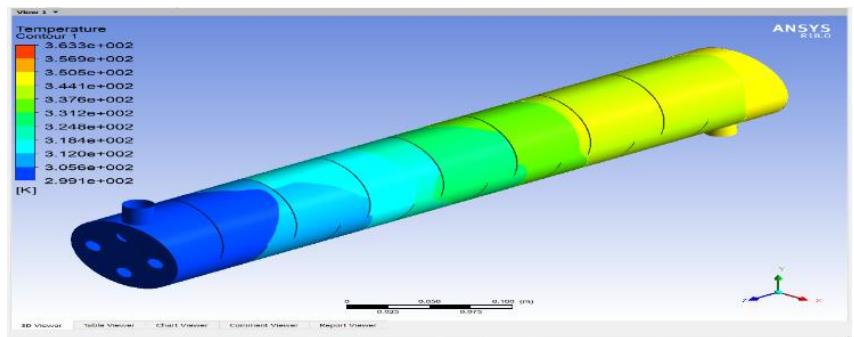

Figure 67 Shell view of 6-Turns CUO model with

14 number baffles of helical tube STHXs

Mesh model-

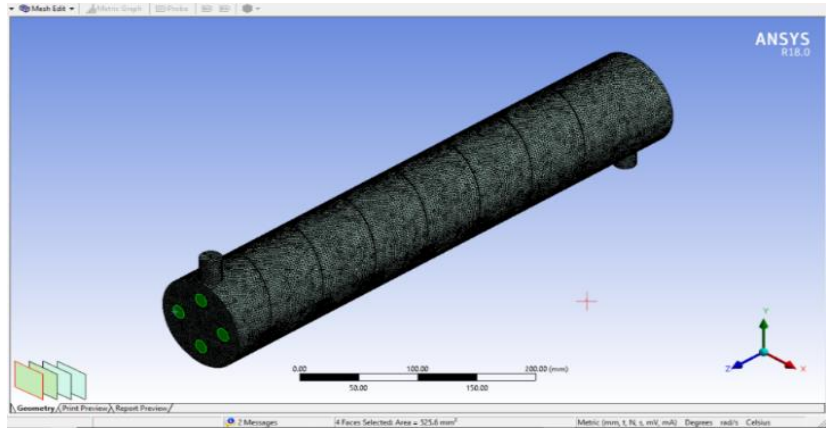

Figure 68 Mesh model of 6-Turns CUO model with 14 number baffles of helical tube STHXs

Temperature curve of both fluids-

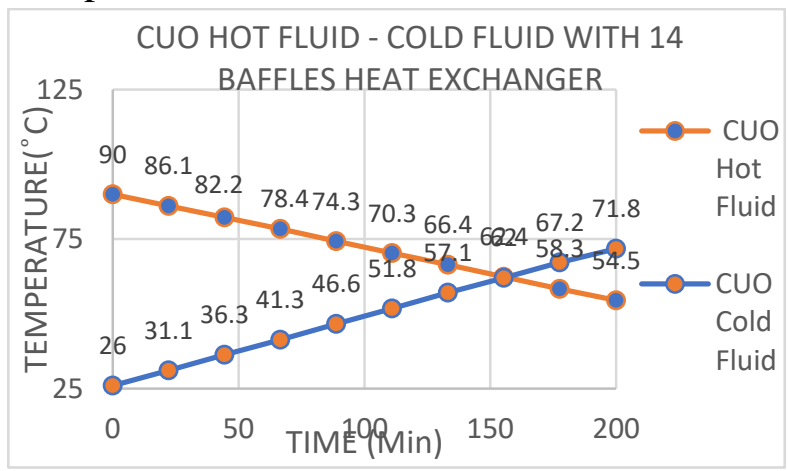

Figure 69 CUO hot fluid - cold fluid with 14 baffles heat exchanger curve 


\section{RESULTS AND DISCUSSION}

Analysis done on both type heat exchangers where cold inlet temperature of fluid in shell side is $26^{\circ} \mathrm{C} 299.15 \mathrm{~K}$ and hot inlet temperature of fluid in tube side is $90^{\circ} \mathrm{C} 363.15 \mathrm{~K}$.

\section{Comparison of Model with and Without Baffle-}

Table 3- For Hot Fluid

\begin{tabular}{|c|c|c|c|c|}
\hline \multirow{2}{*}{$\begin{array}{c}\text { S. } \\
\text { NO. }\end{array}$} & \multirow{2}{*}{ Model } & \multicolumn{3}{|c|}{ Static Temperature } \\
\cline { 3 - 5 } & Number & $\begin{array}{l}\text { Hot } \\
\text { Inlet }\end{array}$ & $\begin{array}{l}\text { Hot } \\
\text { Outlet }\end{array}$ & $\begin{array}{l}\text { Temperature } \\
\text { Difference }\end{array}$ \\
\hline 1 & I & 90 & 81.2 & 8.8 \\
\hline 2 & II & 90 & 79.8 & 10.2 \\
\hline 3 & III & 90 & 78.7 & 11.3 \\
\hline 4 & IV & 90 & 77.5 & 12.5 \\
\hline 5 & V & 90 & 74.1 & 15.9 \\
\hline 6 & VI & 90 & 70.8 & 19.2 \\
\hline 7 & VII & 90 & 84.6 & 5.4 \\
\hline 8 & VIII & 90 & 82.4 & 7.6 \\
\hline 9 & IX & 90 & 84.45 & 5.55 \\
\hline 10 & X & 90 & 82.43 & 7.57 \\
\hline 11 & XI & 90 & 54.54 & 35.46 \\
\hline
\end{tabular}

Table 3- For Cold Fluid-

\begin{tabular}{|c|c|c|c|c|}
\hline \multirow{2}{*}{$\begin{array}{c}\text { S. } \\
\text { NO. }\end{array}$} & \multirow{2}{*}{ MODEL } & \multicolumn{3}{|c|}{ Static Temperature } \\
\cline { 3 - 5 } & NUMBER & $\begin{array}{c}\text { Cold } \\
\text { Inlet }\end{array}$ & $\begin{array}{c}\text { Cold } \\
\text { Outlet }\end{array}$ & $\begin{array}{c}\text { Temperature } \\
\text { Difference }\end{array}$ \\
\hline 1 & I & 26 & 39.9 & 13.9 \\
\hline 2 & II & 26 & 37.9 & 11.9 \\
\hline 3 & III & 26 & 38.4 & 12.4 \\
\hline 4 & IV & 26 & 41.3 & 15.3 \\
\hline 5 & V & 26 & 40.3 & 14.3 \\
\hline 6 & VI & 26 & 44.9 & 18.9 \\
\hline 7 & VII & 26 & 64.7 & 38.7 \\
\hline 8 & VIII & 26 & 65.7 & 39.7 \\
\hline 9 & IX & 26 & 64.7 & 38.7 \\
\hline 10 & X & 26 & 65.6 & 39.6 \\
\hline 11 & XI & 26 & 71.8 & 45.8 \\
\hline
\end{tabular}

In this research, the 6 turn helical tube shell and tube heat exchanger model is more optimised than others. So used different number of baffles in 6 turns helical model. In this model different number of baffle 10 number baffles, 12 number baffles and 14 number baffles used with different pitch and to find which number of baffles is more optimised than others. 


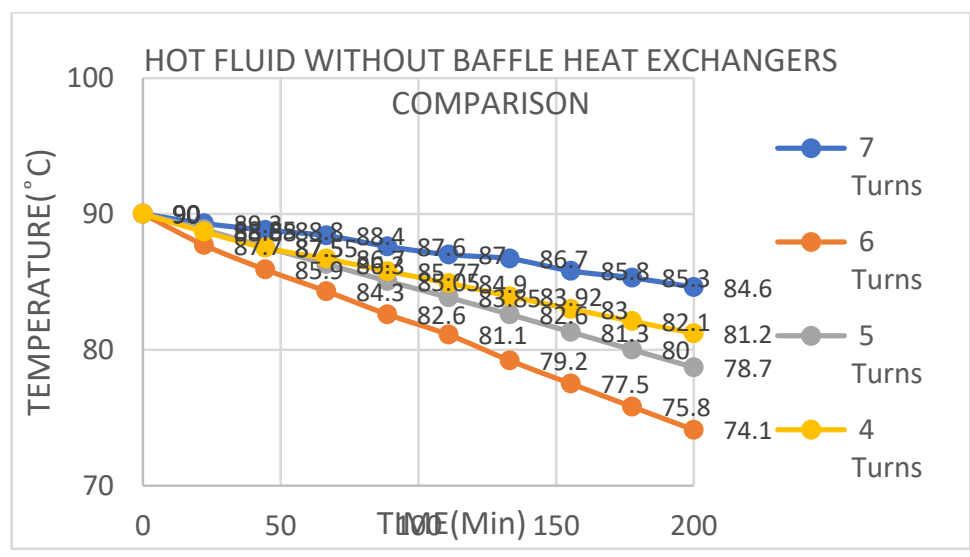

Figure 70 Hot fluid without baffle heat exchanger comparisons

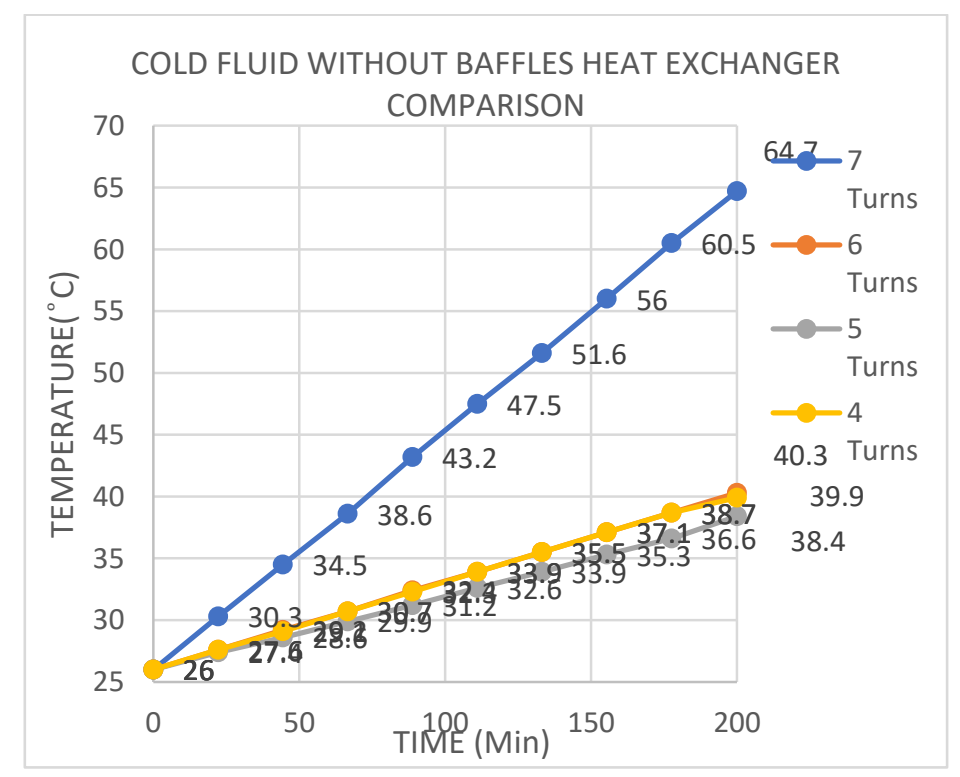

Figure 71 Cold fluid without baffles heat exchanger comparison curve

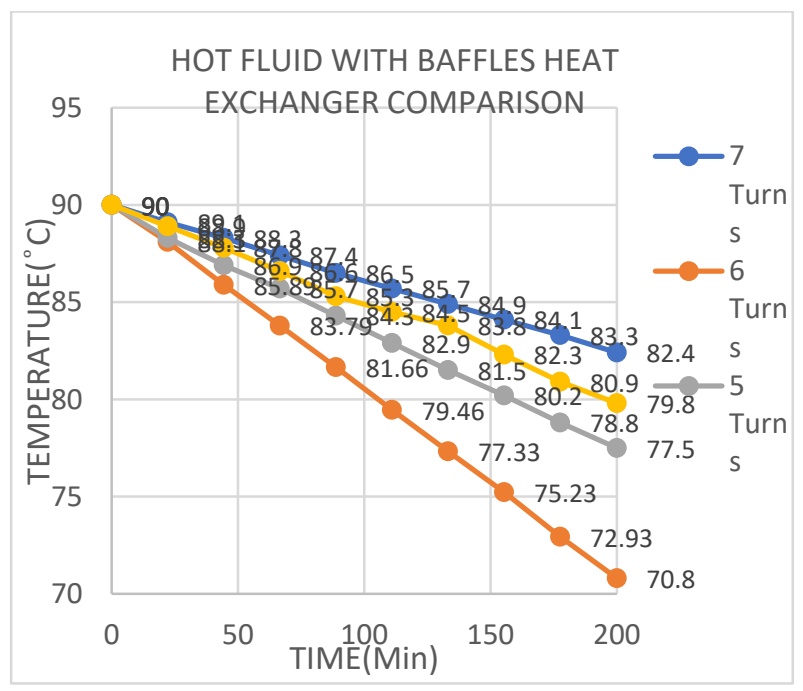

Figure 72 Hot fluid with baffles heat exchanger comparison curve 


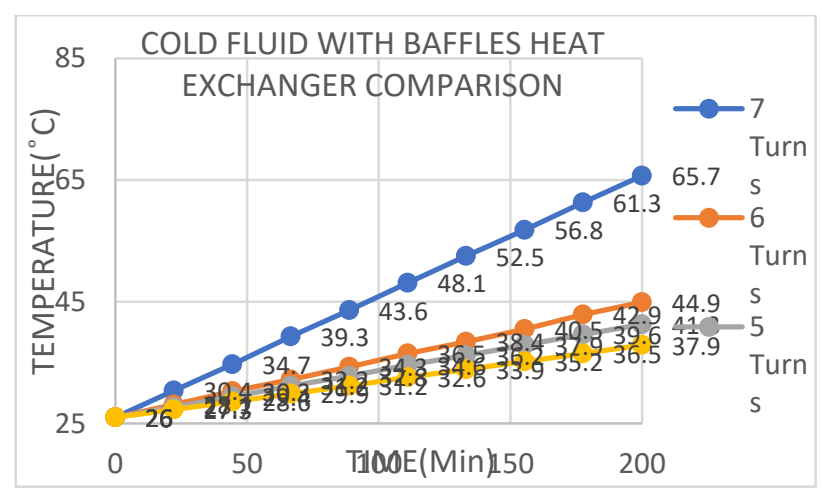

Figure 73 Cold fluid with baffles heat exchanger comparison curve

Table 4- 6 Turns Helical Tube Heat Exchanger

\begin{tabular}{|c|c|c|c|}
\hline \multicolumn{3}{|c|}{$\begin{array}{c}\text { [MODEL-VI]-[MODEL-VII]-[MODEL-VIII] } \\
\text { 6 Turns Helical Tube Heat Exchanger } \\
\text { all values in temperature }{ }^{\circ} \mathrm{c}\end{array}$} \\
\hline Position & $\begin{array}{c}10 \\
\text { Baffles } \\
\text { hot fluid } \\
\text { tube }\end{array}$ & $\begin{array}{c}12 \\
\text { Baffles } \\
\text { hot fluid } \\
\text { tube }\end{array}$ & $\begin{array}{c}14 \\
\text { Baffles } \\
\text { hot fluid } \\
\text { tube }\end{array}$ \\
\hline Inlet temp & 90 & 90 & 90 \\
\hline Outlet temp & 75.3 & 73.2 & 70.8 \\
\hline $\begin{array}{c}\text { Temperature } \\
\text { Difference }\end{array}$ & 14.7 & 16.8 & $\mathbf{1 9 . 2}$ \\
\hline
\end{tabular}

\section{CONCLUSION}

The objective of the study is to enhance the performance of shell and tube heat exchanger without baffle by using optimum baffle condition. The CAD software namely SOLIDWORKS 2017 and analysis software namely ANSYS FLUENT 18 are used for achieving the objective of the research.

$>$ In this research found that with increasing the number of turns the hot fluid temperature difference increase till 6-Turns and in 7-Turns the temperature difference in hot fluid again decrease. Model-VIII is $18 \%$ more optimum than model model-X So, it shows that the quantity of cold fluid present between turns is should be in right amount.

$>$ In 6-Turn more temperature difference see, so this is more optimised model. In this model applied 10, 12, 14 number of discontinuous helical baffles with 50\% baffle cut and found that the 14-number baffle of model have more temperature difference in hot fluid with $0.063 \mathrm{~m}$ baffle spacing.

$>$ In last objective model-XI 6-Turn 14 baffles optimised model the water fluid is replace by the CUO nano fluids and find more temperature difference in hot fluid than model-VIII water fluid 6-Turn 14 baffle heat exchanger model. The model-XI is approx. 25\% more efficient than model-VIII. 
The helical baffle can design in a more optimum way to enhance the performance of the heat exchanger device. In future work use different technique and smart material which forcefully extract heat from hot fluid to cold fluid.

\section{REFERENCES}

Abd, A. A., Kareem, M. Q., and Naji, S. Z. 2018. Performance analysis of shell and tube heat exchanger: Parametric study. Case studies in thermal engineering, 12: 563-568.

Abdelkader, B. A., and Zubair, S. M. 2019. The Effect of a Number of Baffles on the performance of Shell-andTube Heat Exchangers. Heat Transfer Engineering, 40(1-2): 39-52.

Aydin, Ahmet \& Yasar, Halit \& Engin, Tahsin \& Büyükkaya, Ekrem. (2020). Optimization and CFD analysis of a shell-and-tube heat exchanger with a multi segmental baffle. Thermal Science. 293-293. 10.2298/TSCI200111293A.

Dong, C., Chen, Y. P., and Wu, J. F. 2014. Influence of baffle configurations on flow and heat transfer characteristics of trisection helical baffle heat exchangers. Energy conversion and management, 88: 251-258.

Dong, C., Chen, Y. P., and Wu, J. F. 2015. Flow and heat transfer performances of helical baffle heat exchangers with different baffle configurations. Applied Thermal Engineering, 80: 328-338.

Gao, B., Bi, Q., Nie, Z., and Wu, J. 2015. Experimental study of effects of baffle helix angle on shell-side performance of shell-and-tube heat exchangers with discontinuous helical baffles. Experimental thermal and fluid Science, 68: 48-57.

Gugulothu, R., Sanke, N., and Gupta, A. V. S. S. K. S. 2019. Numerical Study of Heat Transfer Characteristics in Shell-and-Tube Heat Exchanger. In Numerical Heat Transfer and Fluid Flow, pp. 375-383. Springer, Singapore.

Jayakumar, J. S., Mahajani, S. M., Mandal, J. C., Iyer, K. N., and Vijayan, P. K. 2010. CFD analysis of singlephase flows inside helically coiled tubes. Computers and chemical engineering, 34(4): 430-446.

Kishan, R., Singh, D., \& Sharma, A. K. (2020). Cfd Analysis of Heat Exchanger Models Design Using Ansys Fluent. 11(2), 1-9. https://doi.org/10.31224/osf.io/drnb4

Lei, Y. G., He, Y. L., Chu, P., and Li, R. 2008. Design and optimization of heat exchangers with helical baffles. Chemical Engineering Science, 63(17): 4386-4395.

Lei, Y. G., He, Y. L., Li, R., and Gao, Y. F. 2008. Effects of baffle inclination angle on flow and heat transfer of a heat exchanger with helical baffles. Chemical Engineering and Processing: Process Intensification, 47(12): 2336-2345.

Ozden, E., and Tari, I. 2010. Shell side CFD analysis of a small shell-and-tube heat exchanger. Energy Conversion and Management, 51(5):1004-1014.

Perone, Claudio \& Romaniello, Roberto \& Leone, Alessandro \& Catalano, Pasquale \& Tamborrino, Antonia. (2021). CFD Analysis of a Tubular Heat Exchanger for the Conditioning of Olive Paste. Applied Sciences. 11. 1858. 10.3390/app11041858.

Shahsavar, A., Rahimi, Z., and Salehipour, H. 2019. Nanoparticle shape effects on thermal-hydraulic performance of boehmite alumina nanofluid in a horizontal double-pipe minichannel heat exchanger. Heat and Mass Transfer, 55(6): 1741-1751.

Stehlík, P., and Wadekar, V. V. 2002. Different strategies to improve industrial heat exchange. Heat Transfer Engineering, 23(6): 36-48.

Stehlik, P., Němčanský, J., Kral, D., and Swanson, L. W. 1994. Comparison of correction factors for shell-andtube heat exchangers with segmental or helical baffles. Heat transfer engineering, 15(1): 55-65. 
Taher, F. N., Movassag, S. Z., Razmi, K., and Azar, R. T. 2012. Baffle space impact on the performance of helical baffle shell and tube heat exchangers. Applied Thermal Engineering, 44: 143-149.

Tran, T. H., and Nguyen, V. T. 2014. Copper oxide nanomaterials prepared by solution methods, some properties, and potential applications: a brief review. International scholarly research notices.

Wajs, J., Mikielewicz, D., Fornalik-Wajs, E., and Bajor, M. 2019. High performance tubular heat exchanger with minijet heat transfer enhancement. Heat Transfer Engineering, 40(9-10): 772-783.

Wang, Q., Chen, G., Chen, Q., and Zeng, M. 2010. Review of improvements on shell-and-tube heat exchangers with helical baffles. Heat Transfer Engineering, 31(10): 836-853.

Wang, S., Wen, J., and Li, Y. 2009. An experimental investigation of heat transfer enhancement for a shell-andtube heat exchanger. Applied Thermal Engineering, 29(11-12): 2433-2438.

Wang, S., Wen, J., Yang, H., Xue, Y., and Tuo, H. 2014. Experimental investigation on heat transfer enhancement of a heat exchanger with helical baffles through blockage of triangle leakage zones. Applied Thermal Engineering, 67(1-2): 122-130.

Wang, Y., Liu, Z., Huang, S., Liu, W., and Li, W. 2011. Experimental investigation of shell-and-tube heat exchanger with a new type of baffles. Heat and mass transfer, 477, 833-839.

Xianhe, D., and Songjiu, D. 1998. Investigation of heat transfer enhancement of roughened tube bundles supported by ring or rod supports. Heat Transfer Engineering, 19(2): 21-27.

Yang, J. F., Lin, Y. S., Ke, H. B., Zeng, M., and Wang, Q. W. 2016. Investigation on combined multiple shellpass shell-and-tube heat exchanger with continuous helical baffles. Energy, 115: 1572-1579.

Tyagi, R. K. M. H. R. 2014. Computational analysis of intensive and extensive properties of Nano fluids. International Journal for Research in Applied Science and Engineering Technology, 2(12): 249-256. 